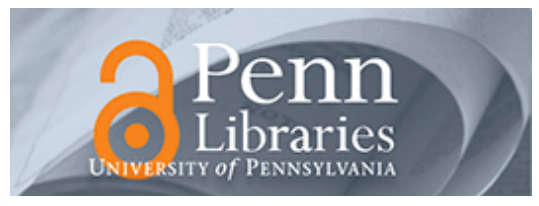

University of Pennsylvania

ScholarlyCommons

Marketing Papers

Wharton Faculty Research

$3-31-2011$

\title{
The Global Warming Alarm: Forecasts from the Structured Analogies Method
}

Kesten C. Green

J. Scott Armstrong

University of Pennsylvania, armstrong@wharton.upenn.edu

Follow this and additional works at: https://repository.upenn.edu/marketing_papers

Part of the Behavioral Economics Commons, Environmental Sciences Commons, Environmental

Studies Commons, Marketing Commons, and the Statistics and Probability Commons

\section{Recommended Citation}

Green, K. C., \& Armstrong, J. S. (2011). The Global Warming Alarm: Forecasts from the Structured Analogies Method. Retrieved from https://repository.upenn.edu/marketing_papers/319

This is an unpublished manuscript.

This paper is posted at ScholarlyCommons. https://repository.upenn.edu/marketing_papers/319

For more information, please contact repository@pobox.upenn.edu. 


\title{
The Global Warming Alarm: Forecasts from the Structured Analogies Method
}

\begin{abstract}
When the beach patrol raises the alarm that a shark has been sighted we know what to do, but how should we respond to an alarm that is based on predictions of what will happen 100 years from now and the person raising the alarm tells us we must make great sacrifices now to avoid the predicted catastrophe? To answer this question, we forecast effects and outcomes of the current global warming alarm using a structured analysis of analogous situations. To do this, we searched the literature and asked experts to identify phenomena that were similar to the alarm currently being raised over dangerous manmade global warming. We obtained 71 proposed analogies. Of these, 26 met our criteria that the alarm be: (1) based on forecasts of human catastrophe arising from effects of human activity on the physical environment, (2) endorsed by experts, politicians and the media, and (3) that were accompanied by calls for strong action. None of the 26 alarms were based on scientific forecasting procedures. None of the alarming forecasts were accurate. Governments took action in 23 of the analogous situations and those actions proved to be harmful in 20 . The government programs remained in place after the predicted disasters failed to materialize. The global warming alarm movement appears to be the latest manifestation of a common social phenomenon: false alarms based on unscientific forecasts of humancaused environmental disasters. We predict that the alarm over forecasts of dangerous manmade global warming will, like previous similar alarms, result in harm.
\end{abstract}

\section{Keywords}

DDT, decision making, evidence-based forecasts, global cooling, lobby groups, popular movements, precautionary principle, public policy, scenarios

\section{Disciplines}

Behavioral Economics | Business | Environmental Sciences | Environmental Studies | Marketing | Statistics and Probability

\section{Comments}

This is an unpublished manuscript. 
The global warming alarm:

Forecasts from the structured analogies method

\author{
Kesten C. Green \\ International Graduate School of Business, University of South Australia \\ GPO Box 2471, Adelaide SA 5001, Australia. \\ kesten@me.com; kestencgreen.com; T +61 88302 9097; F +61 883020709 \\ J. Scott Armstrong \\ The Wharton School, University of Pennsylvania \\ armstrong@wharton.upenn.edu; jscottarmstrong.com; T +1 6106226480
}

31 March $2011 \quad$ AGW88-KG.docx

\begin{abstract}
NOTE: We seek peer review from others, especially with evidence that would challenge our findings or conclusions.
\end{abstract}

\title{
Latest version available at http://kestencgreen.com/green\&armstrong-agw-analogies.pdf SSRN Working Paper Version available at http://ssrn.com/abstract=1656056
}

\begin{abstract}
When the beach patrol raises the alarm that a shark has been sighted we know what to do, but how should we respond to an alarm that is based on predictions of what will happen 100 years from now and the person raising the alarm tells us we must make great sacrifices now to avoid the predicted catastrophe? To answer this question, we forecast effects and outcomes of the current global warming alarm using a structured analysis of analogous situations. To do this, we searched the literature and asked experts to identify phenomena that were similar to the alarm currently being raised over dangerous manmade global warming. We obtained 71 proposed analogies. Of these, 26 met our criteria that the alarm be: (1) based on forecasts of human catastrophe arising from effects of human activity on the physical environment, (2) endorsed by experts, politicians and the media, and (3) that were accompanied by calls for strong action. None of the 26 alarms were based on scientific forecasting procedures. None of the alarming forecasts were accurate. Governments took action in 23 of the analogous situations and those actions proved to be harmful in 20. The government programs remained in place after the predicted disasters failed to materialize. The global warming alarm movement appears to be the latest manifestation of a common social phenomenon: false alarms based on unscientific forecasts of human-caused environmental disasters. We predict that the alarm over forecasts of dangerous manmade global warming will, like previous similar alarms, result in harm
\end{abstract}

Key words: DDT, decision making, evidence-based forecasts; global cooling; lobby groups; popular movements; precautionary principle; public policy; scenarios. 
In 1896 the Swedish Nobel Prize winner in chemistry, Svante Arrhenius, speculated about the effect of increases in atmospheric carbon dioxide $\left(\mathrm{CO}_{2}\right)$ and concluded that higher concentrations would cause warming. His conclusion was drawn from an extrapolation of a small sample of observational data ${ }^{1}$. Arrhenius's idea attracted little attention at the time.

Sawyer (1972) summarized what was then known about the role of $\mathrm{CO}_{2}$ in the atmosphere. He forecast that the $25 \%$ increase in $\mathrm{CO}_{2}$ predicted to occur by 2000 would lead to an increase of $0.6{ }^{\circ} \mathrm{C}$ in world temperature. As best as can be judged from the paper, the prediction was based primarily on Sawyer's unaided judgment. Sawyer's prediction appears to have been correct, in the sense that $\mathrm{CO}_{2}$ concentrations and global mean temperatures increased modestly over that time period according to the available data, which are based on limited samples of temperature readings that have been subjected to unpublished adjustments. Despite questions over the reliability of the data and the refrain that correlation does not prove causation, global warming alarmists seized on this as strong evidence. Meanwhile, they ignored contradictory evidence, such as Soon's (2009) evidence that there was no correlation between atmospheric $\mathrm{CO}_{2}$ and temperature during a similar time period in the Arctic.

Climate change is a complex phenomenon about which there is a great deal of uncertainty. The extent of the uncertainty can be seen in recently published books and papers that examine the physical evidence, such as Carter (2010), Idso and Singer (2009), and Soon (2009). In such situations, empirical research on forecasting has led to a surprising conclusion: scientists' judgments of what will happen are of no value (Armstrong 1985; Tetlock 2005).

Moreover, in complex and uncertain situations, simple forecasting models are superior to complex ones. In situations of uncertainty and ignorance such as climate change, complex and expensive computer models such as those behind the Intergovernmental Panel on Climate Change's (IPCC) climate projections require many judgments on how things work and what will happen. As a consequence, mistakes are likely and accuracy is unlikely. In an earlier paper (Green, Armstrong, and Soon, 2009), we showed that the errors of the IPCC global mean temperature projections were seven times greater for 1-100 year ahead forecasts from 1851 to 1975 than were the forecasts from the simplest of models: assuming temperatures would remain unchanged.

The global warming alarmists' lack of interest in scientific forecasting procedures ${ }^{2}$ and the evidence from opinion polls (Pew Research Center 2008) suggest that global warming alarm is essentially a political movement in the U.S., and elsewhere (Klaus 2009). The global warming alarm is the product of advocacy, rather than of the scientific testing of multiple hypotheses. The advocates use a political slogan, the "precautionary principle," to try to stop any examination of alternative viewpoints. And they remove material from Wikipedia that is not consistent with their views (e.g. Solomon 2009).

In this paper, we are concerned with predicting the outcome of the global warming alarm political movement. To do this we used a forecasting method called structured analogies (Green and Armstrong 2007b) that has been shown to be useful for forecasting decisions in conflict situations. Structured analogies is an appropriate forecasting method when little quantitative data exists, large changes are expected, there is conflict among few decision makers, and similar situations have occurred before. For a brief overview of the logic behind our selection of structured analogies for forecasting the global warming alarm political movement, see the "Selection Tree" at forprin.com.

\footnotetext{
${ }^{1}$ See description on Wikipedia and original paper at globalwarmingart.com/images/1/18/Arrhenius.pdf.

${ }^{2}$ http://blogs.telegraph.co.uk/news/jamesdelingpole/100017393/climategate-the-final-nail-in-the-coffin-ofanthropogenic-global-warming/
} 


\section{Applying structured analogies to the global warming alarm movement}

Analogies are similar situations that occurred in the past. By analyzing previous situations, one might forecast similar outcomes for similar situations in the present day.

While analogies are useful for persuasion, their typical informal use does not contribute to the accuracy of forecasts because people tend to be biased in their search for analogies, their selection of analogies, and the way that they use information from analogies. For example, analogies are often used to support favored forecasts. Despite the common misuse of analogies, we reasoned that analogies do contain useful information about how people have behaved in the past and this information would be useful for forecasting given that the analogies were selected and analyzed in an objective manner.

\section{An evidence-based method for making forecasts about conflicts}

We tested the structured analogies procedure that we developed by obtaining forecasts of decisions in eight conflict situations. We presented descriptions of actual, but disguised or obscure, situations and asked experts, working individually, to think of analogies to the eight "target" situations. Then, for a given situation, we asked the experts to rate how similar the analogous situation is to the target situation. We used a predetermined mechanical rule to make the forecasts; namely we took the outcome of the analogy the expert rated as most similar to the target as that expert's forecast. When experts recognized a situation, their responses were excluded. As part of the experiment's design, we also obtained predictions from experts who used their unaided judgment. That is, they were not given any instructions on how to make their forecasts.

We found that unaided experts' forecasts were, at $32 \%$ accurate when chance accuracy was $28 \%{ }^{3}$. In contrast, $46 \%$ of structured-analogies forecasts were accurate. Among experts who were able to think of two or more analogies and who had direct experience with their best analogy, $60 \%$ of forecasts were accurate. The use of a mechanical rule was crucial to accuracy (Green and Armstrong 2007b).

The structured analogies procedure we used for this study was as follows:

1. Identify possible analogies by searching the literature and by asking experts with different viewpoints to nominate analogies to the target situation: alarm over dangerous manmade global warming.

2. Screen the possible analogies to ensure they meet our stated criteria and that the outcomes are known.

3. Code the relevant characteristics of the analogous situations.

4. Forecast global warming alarm outcomes by using a predetermined mechanical rule to code the outcomes of the analogies.

\section{Identifying possible analogies}

Our search for analogies to the alarm over dangerous manmade global warming started in January 2009. We reviewed literature about previous alarms. We also sought suggestions by sending personal requests to diverse experts, to formal email lists ${ }^{4}$, and to an informal list of 148 experts

3 There were between three and six possible decisions described for these situations.

${ }^{4}$ Climate Science Google group, Climate Science Coalition Yahoo group, CMDNET, ELMAR, IIFdiscussion, JDM Society, PSRT-L, Scientific Study of International Processes (SSIP), speakers at the 2009 
including those scientists skeptical of the alarm over dangerous manmade global warming ${ }^{5}$ and IPCC Working Group 1 authors (Randall, et al. 2007). We also distributed questionnaires at conferences we attended, and posted requests on websites.

Here is how we posed the question to the experts:

"The Intergovernmental Panel on Climate Change and other organizations and individuals have warned that unless manmade emissions of carbon dioxide are reduced substantially, temperatures will increase and people and the natural world will suffer serious harm. Some people believe it is already too late to avoid some of that harm.

Have there been other situations that involved widespread alarm over predictions of serious harm that could only be averted at considerable cost? We are particularly interested in alarms endorsed by experts and accepted as serious by relevant authorities."

By May 2010 we had a list of 71 proposed analogies of varying merits. We received formal responses to our email appeal from 11 experts who proposed 24 unique analogies, and informal responses from an additional four experts whose contributions brought the total to 39 unique analogies proposed by experts. The rest of the proposed analogies were situations that we were familiar with or which we identified in our review of the literature.

Our ongoing review of the literature is being assisted by other authors' surveys of alarms of various kinds. These include reviews by Booker and North (2007), Mazur (2004), Simon (1996, Ch $\left.18^{6}\right)$, and Wildavsky (1995).

\section{Screening the possible analogies}

We screened the proposed analogies to find those for which the outcomes were known and that met the criteria of similarity to the global warming alarm. Our criteria for similarity required situations involving alarms that were:

1. based on forecasts of material human catastrophe arising from effects of human activity on the physical environment,

2. endorsed by scientists and politicians, and in the media, and

3. accompanied by calls for strong action

We independently assessed whether the proposed analogies met the three criteria for selection by searching for and reviewing descriptions of the situations, mostly found on the Internet. The findings in this draft are based on our initial selection of 26 analogies, which are listed in Exhibit 1. The proposed analogies that we rejected are listed on publicpolicyforecasting.com on the Global Warming Analogies Forecasting Project page.

International Conference on Climate Change in New York

${ }^{5}$ http://en.wikipedia.org/wiki/List_of_scientists_opposing_global_warming_consensus

${ }^{6} \underline{\mathrm{http}}: / / \mathrm{www}$. forecastingprinciples.com/index.php?option=com content\&task=view\&id=406\&Itemid=192 
Exhibit 1: Analogies to the alarm over dangerous manmade global warming

\begin{tabular}{|c|c|c|}
\hline & Analogy & Year \\
\hline 1 & Population growth and famine (Malthus) & 1798 \\
\hline 2 & Timber famine economic threat & 1865 \\
\hline 3 & Uncontrolled reproduction and degeneration (Eugenics) & 1883 \\
\hline 4 & Lead in petrol and brain and organ damage & 1928 \\
\hline 5 & Soil erosion agricultural production threat & 1934 \\
\hline 6 & Asbestos and lung disease & 1939 \\
\hline 7 & Fluoride in drinking water health effects & 1945 \\
\hline 8 & DDT and cancer & 1962 \\
\hline 9 & Population growth and famine (Ehrlich) & 1968 \\
\hline 10 & Global cooling; through to 1975 & 1970 \\
\hline 11 & Supersonic airliners, the ozone hole, and skin cancer, etc. & 1970 \\
\hline 12 & Environmental tobacco smoke health effects & 1971 \\
\hline 13 & Population growth and famine (Meadows) & 1972 \\
\hline 14 & Industrial production and acid rain & 1974 \\
\hline 15 & Organophosphate pesticide poisoning & 1976 \\
\hline 16 & Electrical wiring and cancer, etc. & 1979 \\
\hline 17 & CFCs, the ozone hole, and skin cancer, etc. & 1985 \\
\hline 18 & Listeria in cheese & 1985 \\
\hline 19 & Radon in homes and lung cancer & 1985 \\
\hline 20 & Salmonella in eggs & 1988 \\
\hline 21 & Environmental toxins and breast cancer & 1990 \\
\hline 22 & Mad cow disease (BSE) & 1996 \\
\hline 23 & Dioxin in Belgian poultry & 1999 \\
\hline 24 & Mercury in fish effect on nervous system development & 2004 \\
\hline 25 & Mercury in childhood inoculations and autism & 2005 \\
\hline 26 & Cell phone towers and cancer, etc. & 2008 \\
\hline
\end{tabular}

\section{Coding the analogies}

We coded the following aspects of the analogies:

1. Forecasting method.

2. Did the proposed action involve substantive government intervention?

3. Accuracy of forecasts was rated on a -1 to +1 scale $(-1=$ wrong direction, $0=$ no, or minor, effect; $+1=$ accurate)

4. Did substantive government intervention take place, or not?

5. Outcome of government policies to date on the value of their net benefit on a -1 to +1 scale

6. Persistence of government policies, to-date, on a 0 to 2 scale $(0=$ reversed; $1=$ no or little change; $2=$ strengthened $)$ 


\section{Describing the analogies}

In order to facilitate peer review by experts on the analogous situations, we are preparing brief descriptions of each (this task is still in the early stages). The descriptions include the following elements and references to sources of information (we will post the descriptions and our key sources at publicpolicyforecasting.com):

1. Forecasts of impending catastrophe

2. Methods used to forecast the catastrophe

3. Actions called for (actions by government or by others)

4. Salient endorsements of the forecast by scientists and politicians

5. Challenges to the forecast

6. Outcomes of each conflict over the alarming forecast and calls for action, including forecast accuracy

Exhibit 2 provides an example of the description of one of the analogies:

\section{Exhibit 2: Example analogy description}

\section{Title: DDT and cancer}

Date: Started in 1962

Forecast of impending disaster: Based on a book, Rachel Carson's Silent Spring, DDT was claimed to be a dangerous cancer-causing chemical. Publication of the book was followed by what some called a national hysteria. The alarm over forecasts of DDT's harmful effects combined concerns about the health and wellbeing of people with concerns about other species. Papers by scientists purported to demonstrate harmful effects on people from DDT exposure.

Forecasting method: A scenario based on the author's speculations from various pieces of information about the effects of DDT. There was no direct evidence that DDT harmed people.

Actions called for: Governments were asked to ban exports of DDT and World Bank loans would be banned to countries that used DDT.

Endorsements of and challenges to the forecast: Leading scientists from institutions (such as Stanford University), politicians (such as Senator Al Gore,) and a report by a commission appointed by President Carter. The reports of the dangers were widely covered by the mass media.

Outcomes of the conflict: The U.S. Environmental Protection Agency (EPA) banned the use of DDT following an 80-day hearing in 1972. Europe and Africa, under pressure from international agencies, did too. No actual harmful effects on humans have been found to result from DDT. Millions of people have died from mosquito-born diseases such as malaria. The EPA decision was based on two studies of animals: the first could not be replicated and the second used a flawed experimental design.

Sources: Edwards (2004); Roberts, et al. (2010); Waite (1994) 


\section{Findings}

\section{Nature of the forecasting methods}

Recall that one of the criteria for selecting an analogy was that it must have been an alarm based on forecasts of a catastrophe that has yet to occur. We could not find any situations scientific forecasting procedures had clearly been used. Instead, we found that the alarming forecasts were experts' judgments, unaided by evidence-based forecasting methods. They could each be characterized as coming from one of three types of judgmental process, namely: (1) unrealistic mathematical models, (2) extrapolation to a near-zero dose of a genuine effect from a large dose, and (3) extrapolating that a hypothesized weak effect might become important over time or for a large population.

An example of the first judgmental process is Thomas Malthus's unsupported mathematical model of human population and resources. Malthus argued that human population would tend to increase at an exponential rate if unchecked, but that food production would increase only arithmetically. This led him to forecast that without measures to curb population growth, people would be faced with forced population reduction via famine and disease. Our initial analysis suggests that 3 of the analogous alarms were based on forecasts that could be characterized as coming from such a process. ${ }^{7}$

Extrapolating the effects of smoking on lung cancer and heart disease to second hand smoke is an example of the second judgmental process. Although the link between smoking and lung cancer is well established, we were unable to find evidence that exposure to second-hand tobacco smoke leads to increases in these diseases. Our initial analysis suggests that 7 of the analogous alarms were based on forecasts that could be characterized as resulting from extrapolation to a very small dose from the effect of a large dose.

Finally, the third judgmental process is a kind of speculation: "What if there is even just a small effect that might accumulate or that might be important when considered across a large population?" Speculation that low levels of toxins in the environment might be responsible for breast cancer when there was no evidence for this or any plausible biological mechanism could be characterized as coming from such a process. Our initial analysis suggests that extrapolation of a hypothesized weak effect was the most common forecasting procedure, with 16 of the alarms apparently based on this procedure.

\section{Role of government}

Government action was called for in 25 of the 26 analogous situations.

We plan to expand this section in due course.

\section{Coding of outcomes}

We coded the outcomes. For example, the Administrator of the EPA banned DDT in the U.S. in 1972. The U.N. and W.H.O. withheld financial aid from developing countries to force them to stop using DDT. There has been no evidence found of any link between DDT and cancer in people but - without DDT and with substitute insecticides being more toxic and less effectiveinsect-borne diseases have increased leading to millions of additional deaths and widespread

\footnotetext{
7 These initial findings may change as we gain additional information on the analogies and as we obtain peer review.
} 
sickness. Government policies have, as a consequence, been very expensive without any benefits accruing. Some restrictions and bans on DDT-use continue to this day (Persistence $=1$ ). This description draws heavily on Edwards (2004).

The calls for action were followed by the implementation of government policies intended to address the alarm in 23 of the analogous situations. Among the analogous situations in which government action was taken, our initial assessment is that harm was caused by the government policies in 20 (as with DDT, the cost of the policies exceeded benefits) or policies were ineffective or the net effect was uncertain in 3 . In none of the analogous situations were the policies clearly effective.

Inevitably, with such controversial situations as dramatic alarms endorsed by senior scientists and political leaders, there may be differences of opinion even after times predicted for alarming outcomes have passed. As a consequence, we invite peer review on this paper and also ask people to post their ratings of the situations on publicpolicyforecasting.com.

\section{Accuracy of the alarming forecasts}

None of the 26 alarming forecasts that we examined was accurate. Based on analyses to date, 19 of the forecasts were categorically wrong (the direction of the effect was opposite to the alarming forecast), and the remaining 7 of the forecast effects were wrong in degree (no effect or only minor effects actually occurred).

\section{Forecasts from structured analogies}

Our impression from analyzing the analogies is that global warming alarm is just another example in a long history of calamity forecasts similar to those described in Extraordinary Popular Delusions And The Madness Of Crowds (MacKay 1841), such as the "Thames Flood of 1 February 1524."

The media give much attention to alarmists, but little to those who are skeptical of their claims. Alarms tend to fade out of the media as alarming forecasts fail to come true. The global warming movement has persisted despite failed forecasts that dangerous warming will happen quickly. In fact, temperatures have been flat to declining for more than a decade.

The analogies to global warming give the impression that the rate of alarms is increasing over time. Worrying (anticipating threats) is an advantageous trait when it leads to taking action to avoid real threats. We speculate that the increasing ease with which the latest alarms can be disseminated, and the increasing prosperity that provides many people with more time to worry about non-existential threats and to devote their energies to causes of their choosing, has led to an increase in alarms in recent years.

\section{Forecasts about the dangerous manmade global warming movement}

Our analysis of the 26 analogies leads us to the following forecasts about the global warming movement:

1. The predicted disasters will not occur.

2. Costly government policies will continue to be implemented in response to the alarm.

3. The manmade global warming political movement will dissipate over the years.

4. Many government programs will remain in place. 


\section{Discussion}

Of the 26 analogous alarms that met our criteria, all were based on forecasts derived from procedures that violated scientific forecasting standards. Not surprisingly, then, none of the forecasts were correct and all of the actions were harmful. We invite others to review our coding and to propose new analogies. The descriptions of the analogous situations will all be posted at publicpolicyforecasting.com. We are still in the early stages of this paper and we seek peer review, especially if it challenges or corrects our analyses. To date, our broad findings have been insensitive to which of the 71 proposed analogies we include in our analysis.

The analogous alarms typically start with observations (e.g., a single study by Wertheimer and Leeper (1979) reported an apparent association between a proxy measure of electromagnetic exposure and leukemia in children). Speculation leads to stories about what might happen if the trend continues or if the relationship is real, strong, and increasingly prevalent. Stories do not represent a scientific forecasting method and are not, therefore, a proper basis for public policy decisions. ${ }^{8}$ The manmade global warming movement has followed a similar approach.

Although the alarmists claim that their position is based on science, they do not follow the scientific methods when forecasting. For example, they do not provide full disclosure of methods and data, they do not consider competing hypotheses, and they draw conclusions that go beyond the evidence. There are documented cases of alarmists falsifying data and of ignoring relevant data in their analyses. Corrections to their errors are typically ignored and the alarmists resist citing contrary findings. The public release of email correspondence between leading IPCC authors provides some evidence of these behaviors (e.g., see Johnson 2009).

Extraordinarily, many leading alarmists claim that there is no need for them to follow scientific principles. For example, Stanford University biology Professor Stephen Schneider said, "each of us has to decide what is the right balance between being effective and being honest." $\mathrm{He}$ also said "we have to offer up scary scenarios" (October 1989, Discover Magazine interview). Al Gore stated, "I believe it is appropriate to have an over-representation of factual presentations on how dangerous it [anthropogenic global warming] is, as a predicate for opening up the audience to listen to what the solutions are" (May 9, 2006, Grist interview).

Stephen Schneider was active in the efforts to ban DDT, to get governments to act to prevent global cooling and, in recent years, to get the government to act to prevent global warming. In 2009, a filmmaker interviewed Professor Schneider about climate change for the documentary "Not Evil Just Wrong" and asked him why he had switched from global cooling in the 1970s to global warming currently. Stanford University, on Schneider's behalf, prohibited the filmmakers from using the audio and video of the interview (Lee 2009). A number of other people who worked for government action to prevent global cooling are now active in the global warming movement, for example John Holdren and Paul Ehrlich (Tierney 2009) ${ }^{9}$. Going back a century, the first global warmer, Svante Arrhenius, was also a key figure in the eugenics movement, which was an alarmist movement concerned that the human race was threatened by the uncontrolled breeding of the "wrong" people.

\footnotetext{
${ }^{8}$ Scenarios enhance the perceived likelihood that an event will occur. The more specific and detailed they are, the more likely people are to judge that the events portrayed will occur. This occurs despite the fact that, as more details that are added to a forecast, it is logically less likely that the forecast will be correct. (See Gregory and Duran, 2001, for a summary of evidence on the use of scenarios.)

${ }^{9}$ For forecasts from scientists on the first Earth Day in 1970, see http://blogs.news.com.au/heraldsun/andrewbolt/index.php/heraldsun/comments/forty years_of earth_day and armageddon no closer/
} 
We are not the first to say that alarmists are motivated by political rather than scientific objectives (see e.g. Simon 1992). Simon's claim that doomsayers were always wrong and that, in fact, the environment keeps getting better were unbelievable to many people who asked "But what about the other side's data?" Simon's answer: "There are no other data. I invite you to test for yourself [whether] the conditions of humanity have gotten better." Following in Simon's footsteps, we invite you to find any scientific forecasts that support a manmade global warming catastrophe. We have been offering this challenge since 2007 and no one has informed us of such a forecast.

In their efforts to support expensive interventions, alarmists point to the "precautionary principle." The precautionary principle suggests that because an event that advocates say might happen and might have large and harmful consequences, the actions specified by the advocates must be taken. The advocates claim that cost/benefit analyses are not relevant for such a problem, and, given the uncertainty, we must act immediately. Actions are taken to stifle dissent. The "precautionary principle" is the antithesis of science. It is a political principle. The claim that we must act given the uncertainty of the situation was anticipated in George Orwell's 1984, with the slogan on the Ministry of Truth building: "Ignorance is strength."

The burden of proof for government intervention should fall upon the advocates of intervention. In making a case, shouldn't advocates be expected to provide evidence that forecasts of all costs and benefits are based on proper scientific methods and that the methods have been validated for use with the situation of concern to the advocates? To ensure that a scientific approach was used in making the forecasts, each member of the research team should be required to sign an ethical statement that they have expertise in the relevant areas, that they have adhered to the highest scientific standards, and that conclusions that go beyond the data and scientific forecasts represent their personal viewpoints.

\section{Conclusions}

Our earlier research has led us to conclude that people can learn more effectively from history if historical knowledge is analyzed in a structured manner. The structured analogies method provides an evidence-based procedure for doing so.

Using structured analogies, we forecast that the global warming alarm movement, like the previous alarmist movements that we were able to identify and analyze, will continue to produce poor forecasts and cause harm to people. Resources will be used inefficiently, and most people will be worse off than they would have been had the alarm never been raised.

Alarms based on unscientific forecasts are a common social phenomenon. The alarms are used to support political movements. Dissent is punished. Expensive government interventions are frequently recommended and often implemented. Once in place they continue even when the alarming forecasts prove to be groundless, perhaps because a large sector of the economy depends on jobs created to "protect" against the predicted catastrophe.

The dangerous manmade global warming alarmist movement will ultimately fail, but as in the past, there will be similar alarms in the future. Many people will be ready to expound on and believe in forecasts of new disasters. Proper science, which requires fair testing of reasonable alternative hypotheses and reproducible evidence, is the best defense against such false forecasts.

\section{Acknowledgements}

We are grateful to Sonja Boehmer-Christiansen, Daniel Botkin, Max Borders, Bob Carter, Robyn Dawes, Mary Durfee, Robert Fildes, Dave Finney, Viv Forbes, Kirt Griffin, Michael Littlewood, Owen McShane, Randal O'Toole, Roger Sedjo, and James Weir for their suggestions of analogous situations. Kay A. Armstrong, Andreas Graefe, David Legates and Willie Soon 
provided useful suggestions. Soo Lee and Kate Schuh assisted in writing descriptions of the analogies. Kanica Allagh, Alexandra House, and Kelsey Matevish edited the paper.

\section{REFERENCES}

Amstrup, S. C., B. G. Marcot, D. C. Douglas. 2007. Forecasting the rangewide status of polar bears at selected times in the $21^{\text {st }}$ Century. Administrative Report, USGS Alaska Science Center, Anchorage, AK.

Armstrong, J. S. (1985). Long-range Forecasting: From Crystal Ball to Computer. New York: John Wiley.

Armstrong, J. S. (2001). Principles of Forecasting. Kluwer Academic Publishers (Springer).

Armstrong, J. S., Brodie, R., \& Parsons, ??. (2001). Hypotheses in Marketing Science: Literature Review and Publication Audit. Marketing Letters, 12 (2), 171-187.

Armstrong, J.S., K. C. Green \& W. Soon (2008), "Polar bear population forecasts: A public-policy forecasting audit," Interfaces 38, No. 5, 382-405. See also the authors' response: Amstrup, S. C. et.al (2009), "Rebuttal of "Polar bear population forecasts : A public - policy forecasting audit," Interfaces, 39, 353-369. (We were not invited to respond; you can draw your own conclusions).

Booker, C. \& North R. (2007). Scared to death - From BSE to global warming: Why scares are costing us the Earth. London: Continuum.

Bray, D. \& von Storch, H. (2007). Climate scientists' perceptions of climate change science. GKSS Forschungszentrum Geesthacht $\mathrm{GmbH}$.

Carter, R. M. (2010). Climate: The counter consensus. London: Stacey International.

Chamberlin, T. C. (1965). The method of multiple working hypotheses. Science, 148, 754-759. (Reprint of an 1890 paper).

Edwards, J. Gordon (2004), "DDT: A case study in scientific fraud," Journal of American Physicians and Surgeons, 9 (3), 83-88.

Green, K. C. \& Armstrong, J. S. (2007a), "Global warming: forecasts by scientists versus scientific forecasts," Energy and Environment, 18, No. 7+8, 995-1019. Available at http://www.forecastingprinciples.com/files/WarmAudit31.pdf

Green, K. C. \& Armstrong J. S. (2007b), "Structured analogies in forecasting, International Journal of Forecasting, 23, 365-376. Available at http://www.forecastingprinciples.com/files/pdf/INTFOR3581_Publication15.pdf

Green, K. C. \& Armstrong J. S. (2008), "Uncertainty, the precautionary principle, and climate change," (http://prubicpolicyforecasting.com)

Green, K. C., Armstrong, J. S., \& Soon, W. (2009). "Validity of climate change forecasting for public policy decision making," International Journal of Forecasting, 25, 826-832. Available at http://kestencgreen.com/gas-2009-validity.pdf

Gregory, W. L. \& Duran, A. (2001), Scenarios and acceptance of forecasts. In J. S. Armstrong, Principles of Forecasting. Kluwer Academic Publishers (Springer).

Hunter, C. M., H. Caswell, M. C. Runge, S. C. Amstrup, E. V.Regehr, I. Stirling (2007), "Polar bears in the Southern Beaufort Sea II: Demography and population growth in relation to sea ice conditions." Administrative Report, USGS Alaska Science Center, Anchorage, AK.

Isdo, C. \& Singer, S. F. (2009). Climate Change Reconsidered: The Report of the Nongovernmental International Panel on Climate Change. Chicago: The Heartland Institute.

Johnson, K. (2009). Hacked emails show climate science ridden with rancor. The Wall Street Journal, 21 November.

Klaus, V. (2009). Speech at the Washington Times Climate Change Policy Conference. Washington Briefing: Advancing the Global Debate over Climate Change Policy, The Willard Hotel, Washington D.C., November 4. Available at http://www.klaus.cz/klaus2/asp/clanek.asp?id=G2mBVPC6Q3ik

Lee, J. (2009). Filmaker, prof. in spat over film rights. The Stanford Daily, 13 October. Available at http://www.stanforddaily.com/cgi-bin/?p=1034262 
MacKay, Charles (1841), Extraordinary Popular Delusions \& the Madness of Crowds. New York: Three Rivers Press.

Mazur, A. (2004). True warnings and false alarms: Evaluating fears about the health risks of technology, 1948-1971. Washington, DC: RFF.

Nova, J. (2009). Climate Money: The Climate Industry: $\$ 79$ billion so far - trillions to come. SPPI Original Paper. Available from http://scienceandpublicpolicy.org/originals/climate money.html

Oreskes, N. (2004). the scientific consensus on climate change. Science, 306, 1686.

Pew Research Center (2008) “A deeper partisan divide over global warming” News release, May 8. (Downloaded from http://people-press.org/reports/pdf/417.pdf)

Peiser, B. (2005). The letter Science Magazine refused to publish. Available at http://www.staff.livjm.ac.uk/spsbpeis/Scienceletter.htm

Randall, D.A., et al.. eds. Climate Change 2007: The Physical Science Basis. Contribution of Working Group I to the Fourth Assessment Report of the Intergovernmental Panel on Climate Change. Cambridge, UK and New York, NY, USA: Cambridge University Press,

Roberts, D., Tren, R., Bate, R., \& Zambone, J. (2010). The excellent powder: DDT's political and scientific history. Indianapolis, IN: Dog Ear.

Robinson, A.B, Robinson, N.E., and Soon, W. (2007). Environmental effects of increased carbon dioxide. Journal of American Physicians and Surgeons, 12, 79-90.

Sawyer, J. S. (1972). Man-made carbon dioxide and the "greenhouse" effect. Nature 239, 23-26.

Schneider, S. H. (1989). As quoted in an interview in Discover Magazine, October. Available at http://stephenschneider.stanford.edu/Publications/PDF_Papers/DetroitNews.pdf

Schulte, K. M. (2008). Scientific consensus on climate change? Energy \& Environment, 19, 281-286.

Simon, J. L. (1996). The Ultimate Resource 2, Princeton, NJ: Princeton University Press.

Simon, J. L. (1992). Scarcity or Abundance? A Debate on the Environment, http://www.juliansimon.com/writings/Norton/.

Solomon, L. (2009). How Wikipedia's green doctor rewrote 5,428 climate articles. National Post, posted 29 December at http://network.nationalpost.com/np/blogs/fullcomment/archive/2009/12/18/370719.aspx

Soon, W. (2009). Solar Arctic-mediated climate variation on multidecadal to centennial timescales: Empirical evidence, mechanistic explanation, and testable consequences. Physical Geography, 30, 144-184.

Tetlock, P. E. (2005). Expert political judgment: How good is it? How can we know? Princeton, NJ: Princeton.

Tierney, J. (2009), “Holdren's Ice Age Tidal Wave,” The New York Times: TierneyLab, 29 September. Available at http://tierneylab.blogs.nytimes.com/2009/09/29/dr-holdrens-ice-age-tidal-wave/

Tierney, J. (1990), “Betting on the planet," The New York Times, 2 December, 6, 52. Available at http://www.nytimes.com/1990/12/02/magazine/betting-on-the-planet.html?pagewanted=all

Trenberth, Kevin E. (2007). http://blogs.nature.com/climatefeedback/2007/06/

Waite, Donald E. (1994). "Myths and facts about DDT," in D. E. Waite, Environmental Health Hazards, Environmental Health Consultant; Columbus, Ohio.

Wertheimer N \& Leeper E. (1979) Electrical wiring configurations and childhood cancer. American Journal of Epidemiology. 109(3): 273-284.

Wildavsky, A. (1995). But is it true?: A citizen's guide to environmental health and safety issues. Cambridge, MA: Harvard University Press. 